ISSN: 0212-0267

DOI: http://dx.doi.org/Io.I420I/hedu20I534169188

\title{
LO QUE IMPLICA TRANSFORMAR LA UNIVERSIDAD EN PERSPECTIVA DECOLONIZADORA
}

\author{
The meaning of transforming the university \\ from a de-colonizer perspective \\ Magaldy TÉLLEZ \\ Universidad Simón Rodríguez-Venezuela
}

Recepción: Io de diciembre de 20I4. Envío a informantes: I4 de diciembre de 2014.

Fecha de aceptación definitiva: 28 de enero de 2015

Resumen: En este escrito se exponen algunas aproximaciones a la cuestión de la transformación universitaria, desde el vínculo entre universidad y pensamiento decolonizador, asumiendo este vínculo como una dimensión sustancial al abordaje de tal cuestión. Se busca, así, dar respuesta a las siguientes interrogantes: ¿Qué caracteriza la colonización de la universidad y del pensamiento? ¿Qué significa decolonizar el pensamiento y la universidad?, teniendo presente que la «mirada colonial» sigue atravesando la universidad venezolana y, en consecuencia, que preguntas de este tipo tienen que ver con la crisis de racionalidad y de legitimidad que impacta a la universidad y que nos impele a plantear el reto de cómo pensar desde el Sur.

PALABRAS Clave: universidad; transformación universitaria; colonización del pensamiento; colonización de la universidad; universidad decolonizada; pensamiento decolonizador.

AвSTRACT: In this paper some approaches to the issue of university transformation are presented, from the link between university and de-colonizer thought, assuming this thought as a substantial dimension to addressing this issue. The aim is thus to answer the following questions: What characterized the colonization of the university and the thought? What does it means decolonizing the thought and the university? bearing in mind that the "colonial way of looking» continues through the Venezuelan university and, therefore, that such questions have to do with the crisis of rationality and legitimacy impacting the university. Questions that impels us to pose the challenge of how to think from the South. 
KEYWORDS: university; university transformation; thought colonization; university colonization; de-colonized university; de-colonizer thought.

En la creencia, la decisión, el compromiso público y la responsabilidad ético-política se encuentra el principio de resistencia incondicional de la universidad.

J. Derrida

\section{Introducción}

L

OS ESCRITOS DEL SOCIÓlogo VENEZOLANO RigoberTo LANZ, quien dedicó buena parte de su producción intelectual a la transformación universitaria como un proceso inseparable del reto de transformar los modos de pensar, estuvieron recorridos por una pregunta clave: ¿ Podemos finalmente repensar $y$ transformar a fondo la Universidad sin obviar lo fundamental: la "reforma del pensamiento»?

Como podrá apreciarse, esta pregunta está en sintonía con el tono de este escrito en el que expongo algunas aproximaciones a la cuestión de la transformación universitaria, desde el vínculo entre universidad y pensamiento decolonizador, asumiendo que se trata de una dimensión sustancial al abordaje de tal cuestión, siempre abierta e inacabada. Así pues, en estas breves reflexiones busco responder de manera tentativa a dos interrogantes: ¿Qué caracteriza la colonización de la universidad y del pensamiento? ¿Qué significa decolonizar el pensamiento y la universidad? Ambas plantean, desde luego, mostrar en qué consiste esa mirada sobre el mundo y sobre nosotros mismos que se ha caracterizado en términos de «mirada colonial» y que aún sigue siendo reproducida por la universidad. Pero también considerar si estas interrogantes tienen algo que ver con la crisis de racionalidad y de legitimidad que impacta inevitablemente a la universidad y que nos impele a plantear el reto de cómo pensar desde el Sur.

\section{La colonización del pensamiento y de la universidad por la razón racionalista}

Compartiendo los aportes que al respecto han hecho, entre otros, Boaventura de Sousa Santos, Santiago Castro-Gómez, Edgardo Lander y Rigoberto Lanz, puede sostenerse que la mirada colonial sobre el mundo y sobre nosotros mismos se inscribe en una matriz epistémica configurada y desplegada en el curso de la modernidad occidental. Una matriz de racionalidad en la que se entrecruzan la exaltación de la razón, la fe en el progreso y la certidumbre de la marcha lineal de la historia hacia la perfección de la bumanidad, marcando desde el siglo XviII hasta el clima tecnológico del presente, toda una atmósfera cultural operando como un sistema de repertorios de racionalidad que devinieron valores civilizacionales. De ahí que, como afirmara Lanz, no se trata de un modelo o de una corriente de pensamiento, sino de una «matriz de representaciones que aporta las claves para que distintas corrientes se muevan en su seno»; una matriz en la cual la Razón, el Progreso y la 
Historia se instalaron como «categorías fundantes de la lógica del pensamiento y de la sociedad», como sus horizontes de sentido. En esta matriz se inscribe la obsesión por alcanzar un conocimiento universalmente verdadero y válido, que ha sido uno de los empeños más ambiciosos de la ciencia moderna, a cuyos cánones aún se someten las prácticas dominantes de producción y transmisión de conocimientos en la universidad.

Es en dicha matriz epistémica que se instaura el proceso de dogmatización de la ciencia expresado en su legitimación como el único modo de conocimiento válido a partir, entre otros, de los supuestos asumidos como indiscutibles: el conocimiento como representación de la realidad, la objetividad de la ciencia como conocimiento de las causas, la distancia entre el sujeto cognoscente y el objeto de conocimiento como garantía de objetividad, la presunción de que los únicos límites del conocimiento científico son los que derivan del desarrollo de los instrumentos lógico-deductivos o experimentales y la neutralidad valorativa de la ciencia. Tal concepción, que emerge y se consolida con la trama de la formación del sistema-mundo capitalista y la expansión colonial de Europa, impuso la certeza de que el mundo de la naturaleza y el mundo del hombre son mundos ontológicamente desligados, así como la certeza de que la función del conocimiento es ejercer un control racional sobre el mundo natural y social. Es a esta función que se asocia el privilegio del razonamiento analítico como el único método válido para explicar la realidad natural y social.

Este modelo de la ciencia adquirió total hegemonía en el pensamiento occidental y sus instituciones, pasando a ser socialmente reconocido por las posibilidades instrumentales de su racionalidad. Con ello, su legitimación social se produjo cada vez más por sus consecuencias prácticas en un mundo permeado por la racionalidad científica, al punto en que no sólo la ciencia se legitima socialmente por dichas posibilidades, sino que prácticas sociales e instituciones pasan a ser legitimadas por las aplicaciones de la ciencia. De ahí que el despliegue de tal racionalidad comporte ciertos rasgos del desarrollo científico, con impacto institucional, que Edgar Morin identifica de la siguiente manera: la lógica disciplinaria no ajena a los impedimentos que comporta la superespecialización; la compartimentación y fragmentación del saber; la disyunción entre las ciencias de la naturaleza y las ciencias antroposociales, así como sus efectos en los reduccionismos que operan en ellas; la tendencia a la anonimización que acompaña la propensión a la fragmentación, pues el saber ha dejado de ser pensado, reflexionado, para ser destinado a su acumulación en bancos de datos y luego computado por instancias manipuladoras, empresas y Estados; el devenir ignorante de los especialistas respecto de todo aquello que no concierna a su disciplina, con lo cual se renuncia a la reflexión sobre los asuntos vitales de nuestro tiempo, incluyendo la reconfiguración del saber y sus finalidades. De esta manera, el desarrollo científico ha marchado junto al desarrollo de la inconsciencia sobre sus potencialidades sojuzgadoras y mortales, sobre el hecho de que los poderes creados por la actividad científica escapan completamente a los científicos, pues

Lanz, R.: El discurso posmoderno. Crítica de la razón escéptica, Caracas, UCv-CDCH, I993, p. 29. 
«el poder científico fragmentado en la investigación es concentrado en el nivel de los poderes económicos y políticos» ${ }^{2}$.

Estos rasgos han dado cuerpo a una razón mutiladora, reductora de la complejidad de la realidad y de su conocimiento, ciega a las condiciones históricas de su configuración y a su inscripción en las formas de ejercicio del poder en la sociedad moderna. Pero su hegemonía, sin embargo, ha de interpretarse a partir del hecho de que ese poder que la ciencia ejerce en la sociedad es el resultado histórico concreto de ejercicio de las relaciones saber-poder: el poder ejercido por las clases dominantes sobre las comunidades científicas, a los fines de mantener las condiciones en las que su dominio y su privilegio se asientan y reproducen, el poder que se ejerce en el seno de las mismas comunidades científicas, el poder que se ejerce en las instituciones a través de quienes se reconocen como figuras autorizadas para la toma de decisiones por ser portadores del conocimiento científico. En fin, el poder de la ciencia integrado al poder de identificar, vigilar, organizar, clasificar, regular y controlar individuos y poblaciones, como lo muestran los análisis de Michel Foucault, quien mostró que todo saber tiene efectos de poder, de modo que la función principal de las formaciones discursivas dominantes en la modernidad es la de fundar y perpetuar un régimen de verdad que rige las formas de enunciar, clasificar, juzgar, distribuir saberes y sujetos en la red de prácticas y dispositivos de ejercicio del poder. Pues como advirtiera este pensador Foucault, «cada sociedad tiene su régimen de verdad», su «política general de la verdad», que autoriza, legitima e impone determinados discursos como verdaderos, que establece las técnicas y los procedimientos que son autorizados para obtener la verdad, que define la posición de quienes son los encargados de decir qué es lo verdadero o qué lo falso; que opera mediante una serie de separaciones, como la establecida entre lo verdadero y o falso, respecto de las cuales este pensador sugiere tener presente que ellas se sostienen en toda una red «de instituciones que las imponen y las acompañan en su vigencia y que finalmente no se ejercen sin coacción y sin una cierta violencia»³.

La matriz epistémica racionalista que he descrito brevemente ha tenido en la universidad moderna su lugar privilegiado de realización que, desde luego, con ciertas alteraciones aún persiste en nuestros tiempos. La hegemonía de esa matriz se instaló en la lógica disciplinaria que subtiende no solo sus prácticas de investigación y de docencia, sino también su estructura organizativa. En efecto, esta matriz de racionalidad hizo de la disciplina una lógica de producción, organización y transmisión del conocimiento, pues, parafraseando a Morin, la noción de «disciplina» tiene una función organizacional en el seno del conocimiento científico y sus instituciones. La lógica disciplinaria recorta ciertos temas que se instituyen como pertinentes exclusivamente a la disciplina, lo que traduce los cánones de cientificidad propios de cada disciplina, desde los que despliega toda una red de dispositivos de saber-poder que permiten identificar, jerarquizar, distribuir, ordenar e instrumentalizar no sólo ciertos conocimientos, sino también ciertas posiciones de sujetos: la de los profesores que enseñan la disciplina

Morin, E.: Ciencia con Consciencia, Barcelona, Anthropos, 1982, pp. 33-34.

Foucault, M.: El orden del discurso, Barcelona, Tusquets Editores, I980. 
y sus fundamentos, según sus cánones, y la de los estudiantes que aprenden lo que deben aprender. Pero dicha lógica también dispone la estructura organizativa universitaria: estableciendo las fronteras, entre episteme y doxa; entre el conocimiento legítimo o autorizado debido a su «validez científica» y el conocimiento ilegítimo; entre el conocimiento útil y el conocimiento inútil, e instituyendo las distribuciones de sus programas de docencia e investigación conforme a la agrupación de los tipos de conocimiento especializado de la disciplina, haciendo de la universidad una organización compartimentalizada.

Uno de los efectos de poder de los discursos en los que se ha desplegado la modernidad occidental articulada al binomio capitalismo-colonialismo ha sido el de la construcción de la inferioridad social y cognoscitiva de individuos, grupos y pueblos. Tal construcción ha implicado lo que de Sousa Santos plantea como rasgo constitutivo de la razón moderna: su configuración y despliegue como una razón indolente que conlleva la invisibilización y negación de otros modos de pensar, decir, hacer y sentir ${ }^{4}$. El resultado de esta operación ha sido la anulación de plurales formas de la experiencia humana, de entramados cognitivos, afectivos, simbólicos y materiales transmitidos de generación en generación que han resultado válidos para quienes los heredan, proveyendo de sentido su vida. La razón indolente es, así, portadora de una epistemología de la ceguera que inmoviliza y reduce el campo de la mirada acerca del mundo y de nosotros mismos; que silencia, ignora, condena y excluye todo saber no susceptible de ser incluido en los límites de un modo de conocimiento cuyo propósito es el de conocer para controlar y dominar.

La razón indolente elimina cualquier posibilidad de establecer diálogos con saberes provenientes de entornos diferentes al científico, anula lo diferente, lo heterogéneo, lo plural, otras formas de interpretar el mundo que son declaradas como irrelevantes, inútiles, falsas, exóticas o mitológicas, sometidas, por ende, a la invisibilidad epistémica y social. Es la razón indolente la que funciona en prácticas de producción de conocimientos que responden a la monocultura del saber $y$ del rigor científico, según la cual la ciencia, autoproclamada como la única forma de conocimiento válido, es la detentora absoluta de los criterios de verdad y fiabilidad epistémica. Con ello se promueve el exclusivismo científico que establece jerarquías epistémicas que traducen relaciones de saber-poder. Todo lo que no es considerado conocimiento es excluido del canon científico y pasa a formar parte del terreno de la opinión, la conjetura, la apariencia, la imaginación, la costumbre o la creencia, del oscurantismo, del error, del atraso. De ahí que la razón indolente sea, a la vez, razón impotente, pues piensa que nada puede hacerse contra necesidades concebidas como algo exterior a ella y razón arrogante, pues considera que sólo ella es capaz de ejercer una libertad incondicional que la configura como la única forma de racionalidad.

Por ello, De Sousa Santos plantea que la razón indolente o monocultura del saber científico produce un epistemicidio, es decir, la marginación, muerte y olvido de saberes alternativos y, en consecuencia, relaciones de injusticia cognitiva, concepto éste referido a las condiciones de desigualdad, discriminación o exclusión

4 De Sousa Santos, B.: A critica da razâo indolente, Porto, Afrontamento, 2000. 
epistémica y social producidas por un modo de conocer hegemónico global que limita, invisibiliza y priva de reconocimiento y valor a diferentes formas de saber. Un modo de conocer que, animado por el principio de simplificación, anula lo aleatorio, lo paradójico, lo imprevisible e incontrolable, las co-implicaciones, reduciendo así la complejidad de lo real a la simplicidad de interacciones controlables. Este principio, como cabe reiterar, ha sido inseparable de ciertos propósitos del conocimiento científico destinado a controlar, regular, instaurar un orden, dominar y colonizar, lo que en el capitalismo contemporáneo es inseparable de la condición caracterizada por Santiago Castro-Gómez como condición «posmoderna/poscolonial»", en la cual los relatos de legitimación del saber y de la universidad han cambiado radicalmente y ésta se pliega a los imperativos del mercado global. De ahí la importancia de tener presentes los efectos de la racionalidad neoliberal en la universidad, a lo cual haré una aproximación en las notas que siguen.

\section{La colonización del pensamiento y de la universidad por la racionalidad neoliberal}

El neoliberalismo es ante todo un tipo de racionalidad política que implica tecnologías de producción de subjetividades orientadas a la sujeción de individuos y poblaciones mediante la objetivación de sus conductas, codificadas a partir del cálculo racional de costo-beneficio. Forma de subjetividad cuya construcción revela que la clave del neoliberalismo no está dada, siguiendo a Foucault, en el marco del mercado en sí sino en el circuito sociedad-empresa-competencia, en el cual se mueve la teoría del capital bumano que, como sabemos, impactó de manera decisiva a la universidad como espacio no ajeno a la impronta de la racionalidad neoliberal que funciona bajo distintas formas, especialmente si tenemos presente que la hegemonía de los regímenes neoliberales -cruzados por lo que Foucault llama una «política social privatizada»- ha implicado que los límites a la intervención del Estado en la vida social no instauraran nuevas condiciones de libertad individual y colectiva, sino la intervención de formas no estales de dominio y control. De ahí que el neoliberalismo contenga, a su manera, la paradoja de ser en realidad la fuerza principal de otro tipo de poder, más sutil y abarcador, sobre la vida ${ }^{6}$, vinculada a la gradual e incesante colonización de la esfera pública por la esfera la privada, para decirlo en palabras de Zigmunt Bauman.

A propósito del neoliberalismo, cabe resaltar el nuevo tipo de articulación entre el Estado y el mercado, definida en los términos de un fenómeno que implica el hecho de que el Estado se transforme en una instancia lo suficientemente fuerte como para garantizar el despliegue sin cortapisas de una economía neoliberal y la conversión de la sociedad en una sociedad de libre mercado regida por el consumo, el lucro y la competencia. Esta transformación ha tenido

\footnotetext{
Castro-Gómez, S.: La poscolonialidad explicada a los niños, Popayán, Editora Universidad del Cauca, Instituto Pensar, Pontificia Universidad Javeriana, 2005.

"Al respecto, sugiero la lectura de Foucault, M.: «Clase del I7 de enero de 1979", en Nacimiento de la biopolítica, Madrid, Akal Editores, 2009.
} 
como contracara la pérdida parcial de la soberanía estatal, la destrucción del Estado de Bienestar y, por ende, de la capacidad del Estado para generar su legitimidad fundada en la ejecución de políticas sociales. A tales efectos, el neoliberalismo ha requerido de un modelo político ajustado a su lógica, a saber, el modelo de la democracia representativa restringida a un mero procedimiento formal que concede la celebración periódica de elecciones competitivas, en las que los ciudadanos no toman decisiones políticas sino que eligen a quienes deciden, en las que el voto se constituye como un dispositivo que implica un acto de participación política y a la vez una renuncia a la participación activa y directa. De ahí el fenómeno analizado como despolitización de la ciudadanía, un proceso mediante el cual se ha producido la neutralización de los principios que se ponen en juego en la vida democrática, entre ellos, la participación activa en las decisiones que afectan al común y la creación de espacio público. Fundamentalmente, porque la democracia funciona como un mercado electoral en el que los aspirantes a representantes políticos actúan como proveedores que compiten en un libre mercado para lograr el máximo número de votos y los electores-consumidores eligen a los representantes políticos que parecen responder a sus intereses particulares.

Se ha insistido recurrentemente en el peligro de la invasión del agora por parte de los poderes públicos estatales; sin embargo, como sostiene Bauman', donde hoy se desarrollan los mayores peligros y donde se plantea la mayor necesidad de contención es en esa zona que separa y reúne agora y oikos, pues la primera ha sido invadida por lo privado. Tal invasión comporta el desvanecimiento del agora, ya que lo público ha huido de ella y tanto las agencias como los agentes tradicionales de la política se revelan impotentes para traducir asuntos públicos en causas comunes, mientras las nuevas agencias y los nuevos agentes de lo privado operan sin ningún control democrático de los ciudadanos y de las instituciones políticas, aunque sus decisiones afectan a todos. Se trata, en términos más generales, de la invasión de la vida social por parte de agencias no estatales que funcionan de acuerdo con la racionalidad neoliberal, a la cual se anudan no sólo las terribles consecuencias económicas y sociales del neoliberalismo, sino también los embates de una "política de vida privatizada», para decirlo con palabras de Foucault, que ha tenido y tiene como uno de sus principales resultados el desvanecimiento del agora que, con Castoriadis, Bauman define como la esfera de comunicación entre la esfera política y la esfera privada, donde se reúnen lo público y lo privado, donde no solo se ejerce la elección de opciones disponibles, sino también se examina, cuestiona y renegocia el abanico de elección, donde se ejerce la libertad de decidir lo que ha de entenderse por bien común, sociedad justa, democracia, libertad, etc., y la de actuar en consecuencia. De esta manera, para decirlo con de Sousa Santos, se ha producido el empobrecimiento de la indole ética y emancipadora de la democracia y, en consecuencia, la configuración de una democracia de baja intensidad que convive de manera cómoda con la desigualdad y la exclusión social, interpretadas por este pensador como la puesta de manifiesto de la crisis del contrato social de

Bauman, Z.: En busca de política, Argentina, Fondo de Cultura Económica, 200 I. 
la modernidad y del contundente fracaso de las modernas promesas de igualdad, libertad y solidaridad ${ }^{8}$.

La invasión de la vida social por el neoliberalismo es indisociable de los radicales desplazamientos que el mismo y su crisis han provocado en la vida económica, social, cultural y política de las sociedades contemporáneas. Tales desplazamientos constituyen hoy una dimensión decisiva del andamiaje en el que se inscribe el entrecruzamiento de fuerzas que pugnan por mantener y garantizar las reglas del capitalismo neoliberal sin que se tenga nada que proponer, y de fuerzas cuyas $l u$ chas constituyentes, utilizando una expresión de Toni Negri, no solo se expresan como resultados contingentes de conflictos políticos, sino como acontecimientos que despliegan los deseos de nuevas formas de vida y nuevas propuestas políticas. Entrecruzamiento en el que, se quiera o no, se inscribe la universidad actual con sus dilemas y sus desafíos. Hoy, el hecho es que el contexto político que hizo posible la aceptación de la representación como mecanismo democrático se ha hecho añicos como resultado de una estructura global de poder que socava los sistemas de representación, configurados a escala nacional y que, de manera mistificada, pretendían ser representación del poder del pueblo. Así como es un hecho que el imaginario político haya sido colonizado por el neoliberalismo como forma de racionalidad política que conjuga la despolitización y la privatización de lo público con la construcción de subjetividades despolitizadas y privatizadas $\mathrm{y}$, por ende, despojadas de toda potencia de acción política transformadora.

De tal diagnóstico no escapa Latinoamérica y, en particular, Venezuela, pues no podemos obviar que el neoliberalismo implicó, a partir de la crisis de la deuda y del modelo desarrollista, no solo el fin del débil Estado de Bienestar y sus políticas sociales sino también el fin del imaginario político sobre el cual se levantaron las luchas ciudadanas durante las décadas de vigencia de tal modelo. Esta luchas de desplegaron bajo la convicción de que los derechos sociales y políticos son parte de los derechos esenciales de todos los seres humanos, de modo que, siendo parte de su condición de ciudadanos, estaban en el derecho de exigirlos al Estado, por ser una obligación directa del mismo. Sin embargo, cabe recordar que, bajo el Estado de Bienestar, los derechos ciudadanos se estatalizaron quedando bajo el control de las burocracias estatales y de las élites gobernantes que utilizaron la administración de tales derechos para fortalecer las formas clientelares de hacer política, así como para el control y dominación de la ciudadanía.

En América Latina, la instauración de la hegemonía neoliberal no se dio ni se $\mathrm{da}$ sin conflictos entre las fuerzas sociales y políticas que pugnaban y pugnan por la continuidad de la versión social-liberal del capitalismo, de su versión liberal autoritaria o por transformaciones asociadas a una revolución popular socialista. $\mathrm{Y}$, desde luego, no sin fuertes represiones individuales y colectivas por parte de gobiernos tenidos como democráticos. Al imponerse el neoliberalismo se quiebra el débil proceso de democratización social iniciado en la década de los sesenta, se profundiza la crítica al rol social del Estado y se despliegan mecanismos de corte

Véase De Sousa SAntos, B.: El milenio huérfano. Ensayos para una cultura política, Madrid, ILSA, 2005. 
neoliberal que encontrarían un marco propicio para desmantelar el Estado, así como para reestructurar el modelo de acumulación capitalista bajo los cánones del modelo neoliberal. Desde inicios de la década del setenta, los sectores de poder económico y político ya comenzaban a reapropiarse de las interpretaciones neoliberales en torno a las crisis de las democracias, en las que se destacaban como factores desencadenantes de tal crisis las excesivas demandas populares que recargaban al Estado, de manera que el problema fundamental a atacar y detener era el de las formas de «ingobernabilidad» en las que incurría la ciudadanía con su participación y sus demandas. De ahí que las propuestas incorporaran, entre otros aspectos: la reducción -incluso por medios violentos-de las exigencias de participación ciudadana en las que, cabe recordar, tuvo alta presencia la universidad; el recorte del «gasto» en los programas sociales; la disminución de los recursos financieros para las universidades y la progresiva conversión de los centros universitarios en organismos supuestamente más técnicos que políticos, para debilitar la fuerza de las posiciones contestatarias que ponían en cuestión el orden existente.

La universidad en América Latina fue, no obstante, una traba para la apacible implantación del capitalismo neoliberal que suponía, como condición fundamental, la debilitación de los Estados nacionales desarrollistas en pro de un Estado al servicio de la economía global y competitiva de mercado. Aunque, como cabe recordar, ya desde finales de la década de los ochenta fue perdiendo progresivamente su índole contestaria en el proceso mismo en que fue abandonando su condición de espacio de ejercicio del pensamiento crítico articulado a las luchas por la transformación social y política, para asumirse y reformarse conforme al régimen de visibilidad y enunciabilidad inherente a la racionalidad política neoliberal. Así pues, si el destino de la Universidad estuvo ligado a los Estados nacionales y a los proyectos de nación que se percibían como permanentes y con certidumbre de futuro, su sin-destino estaría anudado a la conformación de la sociedad-empresa $\mathrm{y}$, en consecuencia, a la competencia como su regulador general. Con ello, el proyecto de universidad se disolvía en el mundo de la globalización neoliberal que, montada sobre la crisis de las formas del capitalismo desarrollista y el desmantelamiento del Estado de Bienestar, imponía la fórmula «No hay alternativa». Es justamente en este contexto donde se inscribe la imposición dura o blanda del modelo universitario neoliberal como parte fundamental del proceso global de reconfiguración de la hegemonía capitalista en la región, al que le es consustancial la despolitización y la privatización de lo público. Dicho modelo conjuga, entre otras, las siguientes facetas:

- El borramiento de la universidad como espacio público articulado al proyecto nación y su transfiguración como territorio de oferta y demanda de servicios educativos a los individuos en función de un mercado laboral crecientemente complejizado y transnacionalizado, así como de servicios de asesoría a empresas, para lo cual las instituciones deben operar como empresas autofinanciadas, eficientes y competitivas. En tal sentido, lo más destacado de las transformaciones ocurridas en la universidad radica en el giro producido en su orientación, que consiste en la sustitución de una 
concepción con énfasis en el servicio a la nación por otra que acentúa el servicio a los clientes, individuos o empresas; expresión de lo que Foucault llamó «política social privatizadora».

- El despliegue de mecanismos tales como el vertiginoso crecimiento de instituciones universitarias privadas que, al amparo del Estado, se destinan a «absorber la demanda insatisfecha» de quienes pueden financiar sus estudios; el criterio de autofinanciamiento para universidades públicas que dio lugar a la oferta preferencial de servicios a empresas privadas nacionales y transnacionales; o el establecimiento de mecanismos de evaluación centrados en criterios de medición contables de productividad. Se trata de la universidad entendida como unidad-empresa, comportando la adopción de la lógica empresarial en su funcionamiento.

- La «modernización» de la Universidad, percibida en términos de su adecuación a las demandas la economía competitiva de mercado y de la adopción del paradigma tecnoeconómico y tecnoeducativo para enmarcar sus objetivos y prácticas en la «sociedad del conocimiento y la información». Cabe recordar que este enunciado fue un tema recurrente en el abordaje de la universidad como objeto de estudio, aunque pocos se plantearan que se trataba -y se trata- de una era en la cual se ha producido la conversión del conocimiento en la principal mercancía de una economía competitiva de mercado.

- La exigencia de acreditación permanente de la universidad por parte del sector privado, a los efectos de favorecer la inserción de los profesionales y de los conocimientos producidos en el desarrollo económico sustentado en la empresa privada fundamentalmente transnacionalizada.

- La puesta en escena de la diversificación de fuentes de financiamiento que permitan a la universidad una mayor autonomía para su funcionamiento como empresa y, por ende, una menor dependencia del Estado.

- La organización curricular sustentada en la hiperespecialización del conocimiento, conforme a las demandas de la economía competitiva de mercado $y$ en la enseñanza por competencias para lograr una mayor funcionalidad de su «producto»: los profesionales.

Llegados a este punto, puede sostenerse que el proceso de privatización de la educación universitaria, que acompaña su proceso de neoliberalización, va más allá de la reducción del gasto público en educación y la transferencia «del costo del servicio a las familias y usuarios del mismo», en lenguaje neoliberal, del incremento de la oferta privada, o de la subordinación de la actividad académica a las demandas del mercado. En efecto, si bien es cierto que la privatización universitaria se vincula a la reducción del papel del Estado como institución destinada a garantizar derechos sociales y una política de financiamiento restrictivo, hay dimensiones menos visibles que es preciso considerar, pues conciernen al complejo proceso de redefinición de las fronteras entre lo público y lo privado en la educación superior latinoamericana, en el cual el cuestionamiento al sentido público de la acción universitaria hecho por gobiernos neoliberales e intelectuales que asumen la racionalidad política neoliberal se reconoce en una diversidad 
de espacios porosos, tales como la estructuración del trabajo académico y de los campos disciplinarios, las prácticas de docencia, investigación y evaluación, las formas de reconocimiento del papel social que se atribuye a las instituciones de educación superior, la construcción de subjetividades, entre otros.

No ha sido ni es ajena al proceso de neoliberalización y privatización de la universidad la tecnocratización que ha marcado los procesos de reforma universitaria promovidos por los gobiernos neoliberales, una de cuyas evidencias más destacadas es la centralidad atribuida al concepto de calidad, despojado de su dimensión política. En efecto, la aspirada calidad de la educación superior se reduce a la determinación de una serie de estándares de productividad y rendimiento académico, a la implementación de sistemas de evaluación jerarquizantes y excluyentes, a la vinculación de sujeción de la formación y producción científica a las demandas del mercado. Así pues, el proceso de privatización de la educación universitaria se asocia a una concepción tecnocrática y gerencialista de la calidad que, sin duda, opera contraponiendo de manera irreconciliable, por ejemplo, la excelencia académica al acceso democrático a los saberes socialmente significativos, los méritos y la calidad de los aprendizajes previos a la justicia social en la igualdad de condiciones de acceso y permanencia de los pobres en la educación superior, la rigurosidad científica al necesario compromiso social del trabajo académico con las demandas populares. Dicotomías éstas que han contribuido a resquebrajar el sentido público no solo del debate en torno a la calidad de la educación universitaria sino de sus prácticas, de manera tal que la tecnocratización de la universidad es siempre copartícipe del proyecto de la universidad elitista y antidemocrática.

El nuevo escenario abierto con la crisis del modelo de Estado nacional y del proyecto nación tenía que afectar de manera decisiva a la universidad, pues abandonando su visión de largo plazo, disolviendo sus articulaciones con los proyectos nacionales y vaciando su condición de espacio público de libre pensamiento, terminó ajustándose de diversas formas a la lógica neoliberal. Hoy, podemos afirmar que si el neoliberalismo fracasó en el terreno económico y social, no lo hizo en el terreno ideológico y, tal vez, que esto sea el fondo de una paradoja: en países como Venezuela, buena parte de las universidades públicas autónomas que fueran importantes espacios de las luchas intelectuales anudadas a luchas sociales y políticas se han convertido en uno de los pilares de la ominosa oposición a los gobiernos presididos por Hugo Chávez y Nicolás Maduro, que han enfrentado al neoliberalismo de diversas formas, entre ellas los esfuerzos orientados a la republificación de la educación. Pero más allá de ello, en ellas arraiga buena parte de la academia no sólo inconmovible ante los acontecimientos que estremecen al mundo y a lo que acontece en nuestras sociedades, sino contraria a los movimientos populares como fuerzas en lucha que ponen en juego demandas y experiencias de democracia participativa.

Mas en el caso venezolano, no solo en dichas universidades sino también en aquellas que vienen acompañando tales movimientos y adoptando importantes cambios en materia de democratización del acceso y en su conexión con las políticas sociales del Estado, se continúa atados a la lógica disciplinaria y profesionalizante que funda su organización académica, sus currículums, sus prácticas 
de enseñanza y de investigación. En ellas no sólo sigue imperando un modelo epistemológico racionalista que sostiene la producción y reproducción de conocimiento que sigue arrastrando la impronta colonizadora en el campo del saber y que se ha vuelto infecundo para hacerse cargo de los apremiantes y complejos problemas del mundo y de nuestras sociedades, lo que revela su anquilosamiento frente a los cambios epistemológicos y su impacto en la producción y reorganización de los conocimientos, tanto como frente a las transformaciones sociales, culturales, políticas y económicas.

Este estado de cosas revela un panorama nada halagador, pero del que no cabe derivar ni menos asumir la fórmula «no hay alternativas». Por el contrario, sería desastroso si las inercias a la que está atada la universidad y si su impotencia asociada a sus dispositivos de saber-poder no coexistieran conflictivamente con prácticas que traducen búsquedas de formas críticas de su ineludible inscripción en la sociedad; lo que hoy hace de la universidad un campo de tensiones que cruzan su descaracterización intelectual e institucional resultante de su crisis de hegemonía y de legitimación. Esta última referida al hecho, como lo plantea De Sousa Santos, de que la universidad haya dejado de ser «una institución consensual frente a la contradicción entre la jerarquización de los saberes especializados» y las exigencias de democratización que se le hacen desde la sociedad de la que forma parte ${ }^{9}$. Lo que, sin duda, plantea la importancia de pensar y actuar de cara a la reinvención de la universidad.

\section{La posibilidad de una universidad decolonizada y de un pensamiento decolonizador}

Lo primero a considerar es que esta posibilidad se vincula a la pregunta ¿Cómo pensar desde el Sur?, cuya respuesta no es tarea fácil, pues como sostuvo De Sousa Santos en una entrevista ${ }^{10}$ :

[...] el Sur fue colonizado por el Norte y por eso mucha de la racionalidad y de los instrumentos de la racionalidad a través de los cuales la modernidad occidental se impuso, y que fueron básicamente dos, el Capitalismo y el Colonialismo, penetraron profundamente en todo el Sur global, entendiendo que el Sur no es geográfico sino «un Sur metafórico o retórico», en la medida que es una metáfora del conjunto de los pueblos que han sufrido sistemáticamente con el Colonialismo y el Capitalismo.

Desde luego, como prosigue este autor, tal imposición no se produjo sin resistencias y en esta lucha algunas culturas ancestrales se adaptaron, mientras otras persistieron de manera fuerte o débil. De modo que, hoy, el proceso de reivindicación de estas otras formas de pensar, de imaginar el mundo, de estas

9 De Sousa SANTOS, B.: La universidad en el siglo XXI. Para una reforma democrática y emancipadora de la universidad, edición citada, p. I5.

1o http://www.elecodelospasos.net/article-entrevista-a-boaventura-de-sousa-santos-hayotras-formas-de-pensar-modernas-que-no-son-occidentale-99920137.html. 
otras cosmogonías y cosmovisiones suprimidas, silenciadas, implica una serie de rupturas. Entre ellas, con «la idea de que la Modernidad Occidental es la única forma de racionalidad»y con la idea de que «la racionalidad occidental es homogénea», pues el anudamiento entre capitalismo y colonialismo anuló la diversidad de esta racionalidad al excluir la fecundidad de los aportes de pensadores «que dudaban de todas las certezas de la modernidad occidental». De ahí que no sólo se trate de resquebrajar la convicción relativa al monopolio de rigor de la racionalidad cientificista occidental adaptada al binomio capitalismocolonialismo, sino también de "ver que hay otras modernidades occidentales reprimidas», así como de reconocer «que hay otras formas de pensar modernas que no son occidentales y que vienen de pensamientos ancestrales, que son hoy contemporáneas... de una manera distinta...».

Con estos planteamientos, De Sousa Santos llama la atención sobre «la diversidad ecológica y epistemológica del mundo» y, con ello, sobre el hecho de que «la comprensión del mundo es mucho más amplia que la comprensión occidental del mundo», cuestión que no es fácil de admitir y, sobre todo, de practicar, «porque el Sur fue Colonizado» y porque la afirmación del Sur fue en un primer movimiento para afirmar el Norte, mediante la adopción y reproducción de sus pautas culturales. Hoy, sin embargo, resulta vital un segundo movimiento de afirmación del Sur, de sus epistemologías, donde se inscriben «otras maneras de entender el mundo, de entender la gente, lo que es la ontología, lo que es el ser humano, cómo se conforma, cómo vive, cuál es la importancia de la vida cotidiana...», mas no sólo como ideas de epistemólogos o de científicos sociales, sino como fuerzas tejidas en la multiplicidad de movimientos sociales que demandan otra epistemología.

Precisamente, es en relación a este segundo movimiento de afirmación del Sur, donde, a mi juicio, han de inscribirse los vínculos entre universidad decolonizada y pensamiento decolonizador, en los cuales es posible apreciar múltiples facetas, entre las cuales quisiera destacar las siguientes.

\section{I. Desde el punto de vista epistemológico}

No nos es posible seguir obviando la emergencia de nuevos paradigmas de pensamiento cuya puesta en juego en varios ámbitos de conocimiento que dan señales de rupturas con la colonialidad fomentada por la epistemología racionalista, cuya imagen del mundo y de la vida social está siendo impugnada por tales paradigmas. Entre ellos, el paradigma del pensamiento complejo que también comienza a tener lugar en intersticios de la universidad. Se trata de otro modo de pensar que implica la configuración de otra política de la verdad, de otra ética y otra estética del conocimiento que hacen suyos: una razón sensible, es decir, una razón atenta a las señales que ofrece la vida cotidiana y a formas alternativas de saber; una razón compleja, es decir, una razón abierta a la complejidad constitutiva de lo real y de nosotros mismos, haciendo suyos la incertidumbre, el azar, el desconcierto, etc.; y una razón liberadora, es decir, una razón que rompe con los modos en que hemos sido constituidos como sujetos y asume su compromiso ético 
y político con la construcción inacabada de una sociedad de justicia, igualdad, libertad y solidaridad. Al respecto, tengo presentes los aportes de Paulo Freire y de Orlando Fals Borda, quienes desde América Latina han recalado en experiencias universitarias desde su crítica al eurocentrismo colonial de los saberes sociales modernos (disciplinas de las ciencias sociales) y sus replanteamientos de la realidad latinoamericana.

A mi juicio, la fecundidad del paradigma de la complejidad está vinculada al impulso que se dé a la transdisciplinariedad, pues vivimos en un mundo que ya no puede ser entendido desde la lógica disciplinaria que estructura conocimientos analíticos y ve la realidad de manera compartimentada, estableciendo dicotomías que empobrecen el conocimiento de lo real y de nosotros mismos. Sin embargo, en la universidad dicha lógica sigue predominando tanto en la producción de conocimientos como en la formación de profesionales disciplinarios y disciplinados en el sentido foucaultiano (útiles económicamente y dóciles políticamente), con serias limitaciones para pensar complejamente un mundo complejo, y de actuar en consecuencia. De ahí que deberíamos tomarnos en serio las prácticas articulatorias de la transdisciplinariedad que, a diferencia de la interdisciplinariedad, no busca intercambiar conocimientos entre dos o más disciplinas dejando indemne la lógica disciplinaria, sino romper dicha lógica, inscrita en la lógica excluyente de la ciencia occidental, como ha planteado Nicolescu ${ }^{\text {II }}$. En tal sentido, la experiencia de la transdisciplinariedad nos permite vincular las diversas formas de saber, incluyendo aquellos que la ciencia occidental declaró y excluyó como doxa.

Con ello, el proceso de transformación universitaria guiado por la razón sensible, compleja y liberadora, haciendo cuerpo en la conjunción entre pensamiento complejo y transdisciplinariedad implica la apertura de caminos hacia la universidad como un espacio transcultural, compartiendo un concepto de Santiago Gómez Castro, en el que diferentes formas culturales de producción de conocimientos puedan coexistir. Pues tal conjunción es inconcebible e irrealizable sin poner en juego el diálogo de saberes, en el que diferentes formas culturales de conocimiento puedan convivir en el espacio universitario, lo que implicaría una radical ruptura con el colonialismo epistémico de la ciencia occidental. Asumiendo, desde luego, que el diálogo de saberes sólo es posible si enlazamos la decolonización del modo de pensar que sustenta la producción de conocimientos y la decolonización de las instituciones que producen y transmiten conocimientos, para que aquellos saberes excluidos hagan parte de una universidad donde se haga ejercicio de la justicia cognitiva, planteada por De Sousa Santos.

En la universidad que tenemos, sin embargo, no es cosa fácil, pues los cánones de la ciencia occidental que siguen arraigados en aquélla responden a la estrategia colonial de Occidente, a saber, la construcción y puesta en funcionamiento de la dicotomía entre «pueblos bárbaros», anclados en el pasado e incapaces de hacer uso de la razón, y «pueblos civilizados» que miran al progreso y son capaces de hacer uso autónomo de la razón. En tal sentido, puede sostenerse que el proceso de decolonizar la universidad y decolonizar el pensamiento implica, al menos:

"Nicolescu, B.: Manifesto of Transdisciplinarity, Albany, State University of New York, 2002, p. 50 . 
a. Generar nuevas claves para la comprensión del mundo y de nosotros mismos, de los complejos procesos culturales que, con sus paradojas, reorganizan nuestras maneras de ser, de existir, de pensar, de decir y de sentir.

b. Desplegar experiencias de investigación y formación que transgredan la lógica disciplinaria rompiendo con las dicotomías que definen el devenir de racionalismo moderno: sujeto/objeto, individuo/sociedad, normal/anormal, mente/cuerpo, materia/espíritu, naturaleza/cultura, civilización/barbarie, verdadero/falso, razón/sensación, unidad/diversidad, parte/todo, entre otros.

c. Transgredir la fragmentación del conocimiento inherente a la lógica disciplinaria que atraviesa el carácter profesionalizante e hiperespecialista de la formación, haciendo lugar a experiencias transdisciplinarias y transculturales de creación intelectual y de formación.

d. Construir una relación otra con el saber: que interroga lo que se nos da como saber verdadero, que resiste a lo que se nos impone como el único modelo de realidad, de desarrollo, de ciencia, de la política o de la democracia; que restituye su vocación práctica, no como la utilidad del para qué sirve, sino como actitud y gesto intelectual que permita romper con los límites de lo que debe y puede pensarse, de lo que debe y puede conocerse, desde la imposición de una política de la verdad; para cuestionar radicalmente toda forma de dominación, en el orden del saber y del poder. Una relación, en fin, que sea experiencia de transformación de nosotros mismos y no meramente de exterioridad e instrumental.

e. Desplegar experiencias de creación intelectual y de formación que pongan en juego articulaciones Sur-Sur, es decir, lo que De Sousa Santos llama «globalización solidaria» de los pueblos del Sur, contraviniendo el hecho de que la ciencia y la universidad hayan devenido aliados del capitalismo globalizado.

\subsection{Desde el punto de vista ético-político}

Decolonizar el pensamiento, decolonizando la universidad, y viceversa, no es otra cosa que reinventar la universidad. Y es que de reinvención se trata cuando en América Latina y, en particular en Venezuela, vienen desplegándose procesos de transformación sociopolítica asociados a la reinvención de los proyectos de nación y que plantean nuevas responsabilidades sociales y políticas a la universidad, pues tales procesos traducen una voluntad política contrahegemónica que, contrapuesta a la globalización neoliberal, llama a la universidad a recuperar su potencia de creación para ponerse al servicio de los pueblos, no del capital neoliberal. Ello, asumiendo que la lucha entre las exigencias de democratización del saber y su tradicional configuración elitista como formadora de los cuadros políticos y económicos en cada país no tiene por qué resolverse en términos de precarización de sus prácticas de formación y de investigación -o, en términos más amplios, de creación intelectual-, pues ello contradice su democratización como espacio público al servicio de los pueblos en su pulsión transformadora. 
Aquí está en juego nada más y nada menos que el proyecto de una universidad democrática, autónoma, transformadora y popular; asumiendo que ello sigue siendo una tarea pendiente si tenemos en cuenta la persistencia de una universidad con evidentes rasgos elitistas y corporativistas, a la que las palabras democracia y autonomía le han servido de ropaje ideológico para mantener su statu quo. Ante una tarea de tal magnitud es vital asumir la particular consistencia intelectual del debate en torno a la transformación universitaria en tiempos de transformaciones sociales y políticas profundas, pues de lo contrario ocurre que el debate se disuelve en una medición de fuerzas vacías de todo espesor intelectual.

Asimismo, se trata de asumir que ningún proyecto de universidad es ajeno a las fuerzas sociales que se enfrentan en una sociedad atravesada por conflictos de diversa naturaleza y que, por ende, el despliegue de la política en la universidad involucra dos planos diferentes aunque interconectados. Por una parte, el de la política universitaria respecto de sus funciones primordiales y de sus modelos de gobierno y de gestión; por otra, el de la política universitaria hacia sus contextos de acción que, a fin de cuentas, definen el carácter de los vínculos de la universidad con la sociedad de la que forma parte y que remiten a interacciones de naturaleza reproductora o de carácter transformador. Asunto éste que no debería evadirse en el debate en torno a la transformación universitaria, pues resulta tan decisivo como aquellos relativos a las dimensiones epistemológicas, sociales, éticas y pedagógicas, si asumimos que también atañe a las razones políticas que funcionan respecto de la cuestión más amplia de la transformación universitaria en el sentido de su reinvención como espacio público democrático.

Es preciso hacernos cargo de la vital ruptura con el ostracismo social de la universidad debido a su elitismo y a su corporativismo, así como con su incapacidad para interrogarse a sí misma, pues ambas características la vuelven «presa fácil de los seguidores de la globalización neoliberal», como sostiene De Sousa Santos. También, de la imperativa necesidad de contravenir el cortoplacismo en el que se mueve la universidad, recuperando la tarea de pensarla a largo plazo. Ello, asumiendo la íntima ligazón de la universidad con los proyectos de nación -sin nacionalismos-, cuya viabilidad tiene entre sus condiciones fundamentales la inscripción de la universidad en contextos de transnacionalización desde la perspectiva de una "globalización solidaria y cooperativa», en términos del mismo autor, es decir, sin rendirse a la globalización neoliberal. Asimismo, teniendo en cuenta la existencia de intereses hostiles a la revitalización de la universidad pública, su transformación trasciende a la universidad misma, pues involucra su anudamiento con la radical transformación del Estado; de modo que ambas -transformación de la universidad y transformación del Estado- son objeto de una misma controversia.

Dicha reinvención convoca, así, a la construcción de la universidad como un espacio público democrático, donde sus prácticas formativas y de creación intelectual, sus formas de interacción social, así como la toma de decisiones que conciernen a la comunidad universitaria y su gestión académica y administrativa, se abren al debate público donde concurren de manera conflictiva actores individuales y colectivos intra- y extrauniversitarios. De ahí que no sea desde la lógica de los poderes constituidos, universitarios o estatales, desde donde quepa esperar 
tal reinvención, sino desde la activación y articulación de la potencia instituyente de comunidades de pensamiento y de movimientos sociales internos y externos a la universidad, para coadyuvar a la densificación de una cultura democrática en la que el arte de vivir en común sea inseparable de las luchas por la creación de condiciones para vivir una vida digna de ser vivida. En tal sentido, si la universidad venezolana está llamada a jugar un papel fundamental en la construcción de una sociedad donde prive el ejercicio de la igualdad, la justicia, la libertad, la solidaridad, la responsabilidad, la pluralidad, tendría que irse construyendo como una institución social donde prive este mismo ejercicio. Pues el problema de la universidad frente a la complejidad actual hace que lo que esté en juego no sea la producción de conocimiento por el conocimiento mismo ni la capacitación de nuestros jóvenes para los nuevos y cambiantes mercados de trabajo, sino algo más profundo: la capacidad de tener alguna incidencia sobre el acto ético-politico de decidir por nosotros mismos sobre el porvenir de nuestra vida-en-común. Ello supone, entre sus condiciones de posibilidad:

a. El hecho de que la universidad como parte del tejido sociopolítico y cultural en el cual se inscribe pueda contribuir a la comprensión de la compleja configuración de lo social, sus tensiones, sus conflictos, sus problemas; así como a forjar nuevos imaginarios y nuevas prácticas instituyentes de una universidad otra y de una sociedad otra. Lo que implica a su vez la reivindicación del papel de la universidad pública en el abordaje y proposición de formas de resolución colectiva de los problemas sociales, como parte de la asunción de sus compromisos a la vez sociales, culturales, políticos e intelectuales desde una perspectiva anticolonialista, pues como sentencia De Sousa Santos: «La reforma democrática de la universidad tendrá poco sentido si no es, también, una reforma anticolonialista».

b. La revalorización del papel que debe ejercer la universidad como espacio de lucha por una sociedad más justa, lo que supone el reconocimiento de que su predominante configuración como institución cerrada sobre sí misma, elitizada y corporativista, constituye un obstáculo para las transformaciones democráticas. De ahí que se trata de asumir que una universidad al servicio de un proyecto democrático y popular de nación es una universidad abierta para pensar el mundo a partir de estar abierta a pensarse y cambiarse a sí misma; es una universidad comprometida con la construcción rigurosa de saberes abiertos al diálogo con saberes no académicos; es una universidad reconfigurada como espacio público.

c. Asumir, sin ambigüedades, el compromiso social de la universidad que, como planteó Rigoberto Lanz, coloca en primer plano su lucha frontal contra todas las formas de exclusión. En tanto expresión fundamental de esta lucha, es impostergable debatir y buscar alternativas para enfrentar la situación de injusticia que hoy persiste tanto en el acceso a la universidad como en las condiciones convergentes en los logros educativos de quienes acceden a ella. Como sabemos, el ejercicio pleno de la igualdad y la justicia en el campo universitario sigue siendo una tarea pendiente en no pocas instituciones de América Latina y de Venezuela, lo que involucra replantear 
los términos del papel de la universidad en la construcción de una sociedad más justa y democrática, en los procesos efectivos de democratización social, cultural y política. Se trata, así, de una cuestión que se inscribe en la postulación de una irrestricta apuesta cuyos espacios de realización involucran la confluencia de voluntades, las necesarias sinergias intra- e interinstitucionales y, sobre todo, la emergencia de una nueva manera de pensar y objetivar los vínculos entre universidad, sociedad y Estado. Una apuesta que conjuga una dinámica productiva con justicia social y una democracia sustentada en una ciudadanía sin exclusiones, especialmente si nos percatamos de una trampa que consiste en recurrir a la legitimación de la exclusión en el talento, palabra que sustituye los privilegios basados en razones sociales. Si prestamos un poco de atención a los discursos que cruzan las prácticas de exclusión en y desde la universidad elitista, advertiremos que para estos discursos ya no existen excluidos sino incompetentes.

d. El despliegue del ejercicio democrático en la toma de decisiones que conciernen al común y las interacciones con plurales movimientos sociales que interpelan a la universidad y a los universitarios. Se trata de densificar sus relaciones con la sociedad de la que forma parte, fundamentalmente dando respuesta a las exigencias sociales de su democratización, para situarse en las luchas que hacen frente a una historia de exclusión de grupos sociales y de sus saberes, de la que la universidad ha participado mucho antes que en la actual época del capitalismo neoliberal.

e. El ejercicio, más allá de la libertad académica, de una libertad incondicional de cuestionamiento y de proposición, como propone Jacques Derrida, desde la cual la universidad deviene terreno de debate en el que nada de lo que concierna a la universidad como asunto público se salva de ser cuestionado y de ser dicho públicamente, incluso el modo en que se entiende y se ejerce la libertad académica misma.

f. La inacabada construcción de comunidades plurales de pensamiento donde el ejercicio de la responsabilidad ético-política se potencie como faceta de su configuración en tanto espacio público. Comunidades abiertas al diálogo de saberes. En fin, comunidades comprometidas, sin concesiones, arreglos o claudicaciones, con la causa de la construcción de una sociedad justa y radicalmente democrática, porque en el anudamiento entre decisión, compromiso público y responsabilidad ético-política, se encuentra el principio de resistencia incondicional de la universidad, incluso a sí misma.

g. Generar experiencias democráticas en la vida misma de la universidad, cruzadas por la experiencia de la relación de alteridad, de manera que se deje de hablar sobre el otro o en nombre del otro, para hablar con el otro, para imaginar con el otro, para construir con el otro, ese otro al que la lógica de la identidad y de la diferencia ordenadora ha estigmatizado porque escapa a todo poder de control.

h. Quebrantar las heredadas formas de entender y efectuar los vínculos entre el saber y la vida. Ya no el conocimiento como algo que está fuera de nosotros y del cual nos apropiamos en términos de una relación instrumental. 

MAGALDY TÉLLEZ

Ya no la idea de la vida reducida a pura satisfacción de necesidades básicas de supervivencia. Ya no la idea de la relación entre el saber y la vida, reducida a una relación de exterioridad, en la que el valor del saber se torna utilitario. Plantearse el valor y el sentido del saber para la vida, es decir, el valor que tiene comprender nuestras condiciones de existencia, en lo que impide o hace posible vivir una vida digna de ser vivida, no una vida a secas, sino una vida cualificada éticamente, politicamente, estéticamente.

Se trata, así, de plantearnos la transformación universitaria haciéndonos de la complejidad de un proceso que involucra adentrarse en trayectos inciertos, en cuyos recorridos más que en la salida radican las búsquedas fecundas, no otras que las asociadas a la pregunta por el valor y sentido de aquello a lo que llamamos transformación universitaria. Se trata de la reinvención de la universidad como espacio público, de imaginar y practicar ligazones entre búsquedas y experiencias que no pueden ser sino compartidas, sentidas, asumidas, vividas, es decir, sin atarnos a fórmulas dadas, sin determinarlas de antemano, sin deslumbrarnos fácilmente frente a modelos que se nos presentan y aceptamos como imperturbables. Búsquedas que involucran un otro saber y una otra relación con el saber. Porque lo que está en juego es la capacidad de la universidad de reinventarse a sí misma, es asumir con todas sus consecuencias que estaremos verdaderamente perdidos si el debate, los compromisos y las puestas en escena de la transformación universitaria no están cruzados por la transformación del modo mismo de pensar, pensarla $y$ pensarnos; de decir, decirla y decirnos; de hacer, hacerla y hacernos; de sentir, sentirla y sentirnos.

En pocas palabras, se trata de subvertir el orden de saber-poder instituido, que implica asumir un modo de pensar y de hacer que no solo subvierta las dicotomías asociadas al racionalismo y su lógica disciplinaria, sino que involucre el ejercicio de la democracia universitaria, el ejercicio de la ciudadanía universitaria, es decir, hacer de la vida universitaria una vida democrática. Sin ello, seguirá siendo una gran mentira que nos hacemos a nosotros mismos decir que contribuimos a la democracia por venir.

Colocaré el punto final a este escrito con unas palabras de Rigoberto Lanz ${ }^{\mathrm{I2}}$ :

Me parece que, sin tener claro el modelo nuevo, de cuál es la fórmula para armar esta nueva universidad, porque no hay ningún formato que diga hágase esta o esta cosa para que esto se logre, sin embargo, hay algunas ideas sueltas que me importa poner en la mesa para encarar en serio a qué nos referimos con otro modelo de universidad. Saber lo que no queremos ayuda mucho, saber por dónde van los tiros ayuda mucho, me parece que una de las carencias más dramáticas que tenemos hoy es que nuestra universidad, todas ellas, no hacen más, casi nada más que formar, y está por verse esto de formar, formar profesionales. Esa es una lamentable caricatura adonde derivó lo que tenemos como universidad. Casi lo único que se hace es formar profesionales y esa es una entre otras de las tareas de la universidad pero no su tarea principal. En eso no consiste una universidad, en solo formar profesionales.

12 Palabras dichas durante su intervención en el Foro "Hacia la transformación universitaria», realizado en Caracas por el Centro Internacional Miranda, el I4 de febrero de 201 I. 
El docentismo y el profesionalismo es una derivación producto de la decadencia de la universidad... Esa universidad no tiene vida, ni el estilo... ¿Frente a eso qué? ¿Frente al docentismo profesional, qué? lo esencial de mi proposición consiste en que la universidad que inventemos deben ser comunidades intelectuales. Si las universidades no son comunidades intelectuales pues, no hay forma de no ser un aparato que forma solo profesionales, un aparato que entrena, un aparato que adiestra, una universidad que consista en eso no tiene chance de sobrevivir a la época en la que estamos. Entonces, comunidades intelectuales. Es decir, si la universidad debe definir, todo espacio que se organiza alrededor de las ideas, del pensamiento, de las grandes preguntas, de las agendas del país y del mundo, que anima la reflexión, que anima la búsqueda. ¿Qué es la universidad? Dice la ley: una comunidad que busca la verdad, no, no, no, eso es un anacronismo casi ridículo, buscar la verdad. Pero la verdad huye de su hogar, la verdad huye, la verdad no se encuentra. No, ninguna búsqueda la verdad. Sería un espacio donde la gente se reúna, se junta porque comparte preguntas, porque se hace preguntas en común, porque comparte preocupaciones, porque se plantea unas interrogaciones que los mueven, porque crean ideas, porque inventan cosas, porque resuelven cuestiones, en fin, comunidades intelectuales. ¿Qué es una comunidad intelectual? Eso, una reunión de gente que comparte preguntas, que comparte agendas, que comparte investigación, que comparte búsqueda de salidas para los problemas inmediatos o menos inmediatos, para los grandes problemas o los pequeños problemas; eso va a depender de cada espacio. Pero si no tenemos universidades formadas así, esencialmente gente volcada con una enorme pasión por la producción de conocimientos, por la creación de saberes, obviamente que eso será cualquier otra cosa, menos una universidad que sobreviva al siglo XxI.

Que palabras de Rigoberto hayan sido colocadas para iniciar y culminar este escrito se debe no sólo a su pertinencia en el marco del mismo, sino en lo fundamental como un pequeño homenaje a este entrañable amigo que apostó y se batió por una transformación radical de nuestra universidad desde la perspectiva de las luchas contra toda forma de dominación. 